Article

\title{
Effects of Sports Activity on Sustainable Social Environment and Juvenile Aggression
}

\author{
Younyoung Lee ${ }^{1}$ and Seijun $\operatorname{Lim}^{2, *}$ \\ 1 Department of Police Science, Seoul Digital University, 424, Gonghang-daero, Gangseo-gu, \\ Seoul 07654, Korea; youngcnn@naver.com \\ 2 College of Physical Education, KyungHee University, 1732, Deogyeong-daero, Giheung-gu, \\ Yongin-si, Gyeonggi-do 10315, Korea \\ * Correspondence: sjlim@khu.ac.kr; Tel.: +82-10-5758-8898
}

Received: 23 March 2019; Accepted: 9 April 2019; Published: 16 April 2019

check for updates

\begin{abstract}
It is believed that sports, as a social institution, are one of the most critical extracurricular activities for adolescent as they teach the rules and disciplines. However, the effects of sports participation on adolescent development are still controversial at the level of theoretical and empirical perspectives in sociology and psychology. For this reason, this study focused on the causal relationships among sports activity, social and environmental factors, and juvenile aggression based on empirical research to examine the effects of sports on adolescents. For this purpose, this research used the Korean Children \& Youth Panel Survey (KCYPS) which surveyed 2378 adolescents by multi-stage stratified cluster sampling from 98 schools across South Korea. The data was analyzed by reliability analysis, correlation analysis, exploratory factor analysis, multiple regression, and path analysis with SPSS ver. 23.0 program for Windows. The results were as follows: Firstly, sports activity had a statistically significant effect on the sustainable social environmental factors, and teacher and friend relationships. Secondly, it was found that sustainable social environment had a statistically significant effect on juvenile aggression toward others and oneself. Lastly, sports activity also showed an indirect effect on juvenile aggression toward others and oneself. This means that sports activity affects juvenile aggression through a sustainable social environment. In detail, more sports activity could positively improve one's relationships with teachers and friends and then reduce aggression toward both others and oneself.
\end{abstract}

Keywords: juvenile aggression; stainable social environment; sports activity

\section{Introduction}

Society has undergone a rapid change in which adolescents are have increasingly suffered from balancing development and social adaptation. As a result of these difficulties, juvenile aggression is becoming a severe social problem [1,2]. Juvenile aggression is a complex multifactorial phenomenon with risk factors in the individual, family, social, and the community/society domains [3,4]. More recently, youth policymakers have become interested in the use of sports in aggression prevention programs. Sports-based interventions are perceived as low-cost and non-stigmatizing programs that positively influence youth development [5-7]. Nowadays, local governments and institutions all over the world are offering youth sports activities to prevent juvenile aggression [8,9]. Also, sports participation and the development of adolescents are the main research topics in sociology and psychology because they are strongly related to socialization in schools. Sport is a fundamental social component of politics, economy, and culture. Additionally, physical activity as sports in a similar vein is now growing as an important factor in the prevention of health and psychological problems. For this reason, the educational function of sports is increasingly important about decreasing juvenile 
delinquency, and the positive and negative effect of sports has been studied intensively. As Feldman and Matjasko argued, sports are among the most popular extracurricular activities [10]. The issue of socialization through sports is subject to emerge as the social and educational aspect.

However, despite the significant role of sports in the development of adolescents in the field of school education, little is known about the relationship between sports participation and juvenile aggression. According to most prior researches about the function of sports, it can be said generally that sports might be an effective way for adolescents to be positively involved in school as carrying out the role of social control [11,12]. In this context, Mutz and Baur quoted that sports participation might help in preventing adolescents from aggression and violence [13]. It means that well-programed sports participation helps not only academic knowledge and sociability, but also physical, personal, and cultural development which is needed for social adaptation. From this perspective, sports is accepted as a necessary social factor.

Another theory focusing on the social domain of juvenile aggression is the sustainable social environment theory, which has dealt with relationships with teachers and friends. The higher the attachment to friends and teachers, the better students adapt to school [14]. The positive relationships with teachers and friends influence the overall behavior of adolescents including cognitive and emotional aspects [15-17]. Therefore, it is expected that the relationships with teachers and friends are an essential factor influencing juvenile aggression. Based on these assumptions, this study aims to examine the causal relationships between sports activity, sustainable social environment factor, adolescent relationships with teachers and friends at school, and aggression as a kind of antisocial behavior.

The following are the questions guiding this study:

1. Are there significant causal relationships between sports activity, sustainable social environment factors (relationships with teachers and friends), and juvenile aggression (toward others and oneself)?

2. Is there a mediating effect of sustainable social environment factor (relationships with teachers and friends) between sports activity and juvenile aggression (toward others and oneself)?

\section{Materials and Method}

\subsection{Participants}

This research used data from the Korean Children \& Youth Panel Survey (KCYPS) by National Children \& Youth Policy Institute (Sejong-si, Korea), which was conducted for seven years from 2010 to 2016 with a longitudinal design for fourth-year students in elementary school. The 2016 (6th wave) data from the third-year students in middle school were used in this study. From the sixth wave data, 2378 adolescents from the third year of middle school were selected by multistage stratified cluster sampling from 98 schools across South Korea, and the national survey was conducted face-to-face by interviewers from October to December in 2015 [18]. The detailed information about participants can be seen in Table 1, and socioeconomic backgrounds were used as control variables for this study. The proportion of boys $(1091,52.9 \%)$ and girls $(970,47.1 \%)$ within the study sample was nearly the same. Regarding the economic level, $62.9 \%$ of respondents said they are middle class, and $27.4 \%$ of respondents said that they are high-income class. 
Table 1. Descriptive statistics for participants.

\begin{tabular}{ccc}
\hline Category & \multicolumn{1}{c}{ Answer } & $\%(n)$ \\
\hline \multirow{2}{*}{ Gender } & Boys & $52.9(1091)$ \\
\cline { 2 - 3 } Economic level & Girls & $47.1(970)$ \\
\cline { 2 - 3 } & High-income class & $27.4(565)$ \\
\cline { 2 - 3 } & Middle class & $62.9(1296)$ \\
\hline \multirow{2}{*}{ Mother's education level } & Low-income class & $8.4(200)$ \\
\cline { 2 - 3 } & High school graduation & $47.4(918)$ \\
\cline { 2 - 3 } & College graduation & $49.8(966)$ \\
\hline \multirow{2}{*}{ Father's education level } & High school graduation & $41.0(782)$ \\
\cline { 2 - 3 } & \multicolumn{2}{c}{ College graduation } \\
\cline { 2 - 3 } & Graduate school graduation & $53.4(1019)$ \\
\hline
\end{tabular}

\subsection{Statistical Analysis}

Researchers conducted data analyses to investigate the causal relationships between sports activity, sustainable social environment factors (relationships with teachers and friends), and juvenile aggression (toward others and oneself). Descriptive statistics, factor analysis, reliability tests, Person's correlations, and multiple regressions were performed. To test the mediation role of the relationships with teachers and friends in the association between sports activity and juvenile aggression, researchers conducted a path analysis by using SPSS version 23.0 program.

\subsection{Variable Measure}

All the measures used in this study were based on an individual interview investigation with a self-reported scale. The final collected data were investigated between October and December 2016.

\subsubsection{Control Variable}

In this study, control variables were height, weight, economic level, and parents' educational level as the socioeconomic status. The economic level was measured by household income during the past one year from the date of investigation. Each educational level of mother and father was separately measured by five nominal scales of middle school education, high school education, junior college, college, and graduate level.

\subsubsection{Independent Variable}

The involvement of physical education (PE) classes as sports activity were measured by a single observed item that focused on the respondents' evaluations of how many hours they were actively involved in PE classes in a week. Response options originally consisted of 0 to more than $4 \mathrm{~h}(1=$ never, $2=1 \mathrm{~h}, 3=2 \mathrm{~h}, 3=4 \mathrm{~h}, 5=$ over $4 \mathrm{~h})$ and this study reversed those responses for analysis ( $5=$ never, $4=1 \mathrm{~h}, 3=2 \mathrm{~h}, 2=4 \mathrm{~h}, 1=$ over $4 \mathrm{~h}$ ). According to the frequency-analyzed results, $16.7 \%$ of respondents answered that they did not exercise hard during PE classes and $18.9 \%$ of respondents answered that they actively participated in PE classes more than $3 \mathrm{~h}$ a week.

\subsubsection{Mediating Variable}

The mediating variable in this study was a sustainable social environment factor which was estimated by friends relationship with four items and teacher relationship with five items on a 4-point Likert scale ( 1 = very untrue, $4=$ very true). The questions about friends-self relationship included "Get along well with classmates," "Say sorry in advance when I fight with a friend," "Lend or share 
my textbook or materials if classmates do not have it" and "My friends follow me when I play or go group activities with them." In addition, the questions about teachers-self relationship included "Say hello warmly when I meet teacher", "I feel comfortable to talk with my teacher", "I am glad to meet my teacher out of school", "I feel that my teacher is kind to me", "I hope my homeroom teacher can teach me next year".

\subsubsection{Dependent Variable}

Juvenile aggression as a dependent variable was measured by six items. It consisted of two sub-variables, toward others and oneself. Measuring the aggression toward others consisted of three questions: "I sometimes pick on even small thing", "I sometimes disturb other's works", "I nitpick or run at somebody if they make me preclude what I want" Measuring the aggression toward oneself also involved three questions: "I sometimes fight due to trivial thing", "I am sometimes angry all day long", "I sometimes cry without any reason". Response options were measured using a 4-point Likert scale ( $1=$ strongly agree, $4=$ strongly disagree). Table 2 shows the results of factor analysis on the variables.

Table 2. Factor loadings of perceptual scales.

\begin{tabular}{|c|c|c|c|c|c|}
\hline Constructs & Measurement Items & $\begin{array}{l}\text { Factor } \\
\text { Loadings }\end{array}$ & Component & $\begin{array}{l}\text { Eigen } \\
\text { Value }\end{array}$ & CFV \\
\hline \multirow{4}{*}{$\begin{array}{l}\text { Friend } \\
\text { relationship }\end{array}$} & Get along well with classmates & 0.825 & 0.681 & \multirow{4}{*}{2.233} & \multirow{4}{*}{55.829} \\
\hline & $\begin{array}{l}\text { Say sorry in advance when I fight } \\
\text { with a friend }\end{array}$ & 0.791 & 0.352 & & \\
\hline & $\begin{array}{l}\text { Lend or share my textbook or } \\
\text { materials if classmates do not have it }\end{array}$ & 0.757 & 0.626 & & \\
\hline & $\begin{array}{l}\text { My friends follow me when I play or } \\
\text { go group activities with them }\end{array}$ & 0.594 & 0.573 & & \\
\hline \multirow{5}{*}{$\begin{array}{l}\text { Teacher } \\
\text { relationship }\end{array}$} & $\begin{array}{l}\text { Say hello warmly when I meet } \\
\text { the teacher }\end{array}$ & 0.85 & 0.581 & \multirow{5}{*}{3.321} & \multirow{5}{*}{66.417} \\
\hline & $\begin{array}{l}\text { I feel comfortable to talk with } \\
\text { my teacher }\end{array}$ & 0.839 & 0.705 & & \\
\hline & $\begin{array}{l}\text { I am glad to meet my teacher out } \\
\text { of school }\end{array}$ & 0.812 & 0.723 & & \\
\hline & I feel that my teacher is kind to me & 0.808 & 0.66 & & \\
\hline & $\begin{array}{l}\text { I hope my homeroom teacher can } \\
\text { teach me next year }\end{array}$ & 0.762 & 0.653 & & \\
\hline \multirow{3}{*}{$\begin{array}{l}\text { Aggression } \\
\text { toward others }\end{array}$} & I sometimes pick on even small things & 0.818 & 0.672 & \multirow{3}{*}{3.088} & \multirow{3}{*}{51.461} \\
\hline & I sometimes disturb other's works & 0.794 & 0.688 & & \\
\hline & $\begin{array}{l}\text { I nitpick or run at somebody if he } \\
\text { makes me preclude what I want }\end{array}$ & 0.762 & 0.631 & & \\
\hline \multirow{3}{*}{$\begin{array}{l}\text { Aggression } \\
\text { toward self }\end{array}$} & I sometimes fight due to trivial thing & 0.849 & 0.618 & \multirow{3}{*}{1.002} & \multirow{3}{*}{68.165} \\
\hline & I am sometimes angry all day long & 0.826 & 0.753 & & \\
\hline & I sometimes cry without any reason & 0.62 & 0.726 & & \\
\hline
\end{tabular}

\section{Results}

\subsection{Descriptive Statistics}

Descriptive statistical analysis for this study and response category for each variable are provided in Table 3. The mean of the sum for sports activity was $2.86(\mathrm{SD}=1.39)$. The mean of the sum for the friend relationship was 7.32 ( $\mathrm{SD}=1.74)$, and the teacher relationship was $9.80(\mathrm{SD}=2.98)$ for the sustainable social environment. The mean aggression toward others was 8.90 ( $\mathrm{SD}=1.89$ ), and aggression toward self was $9.50(\mathrm{SD}=1.83)$ for juvenile aggression. 
Table 3. Descriptive statistics for demographic variables.

\begin{tabular}{ccccc}
\hline Variables & Range & Mean & SD & Cronbach's $\alpha$ \\
\hline Sports Activity & $1-5$ & 2.86 & 1.39 & 1 item \\
Friend relationship & $4-16$ & 7.32 & 1.74 & $0.722 / 4$ items \\
Teacher relationship & $5-20$ & 9.80 & 2.98 & $0.871 / 5$ items \\
Aggression toward others & $3-12$ & 8.90 & 1.89 & $0.759 / 3$ items \\
Aggression toward self & $3-12$ & 9.50 & 1.83 & $0.752 / 3$ items \\
\hline
\end{tabular}

\subsection{The Correlation for Sports Activity, Sustainable Social Environment, and Juvenile Aggression}

Researchers analyzed the correlation among the independent, dependent, and mediation variables to examine whether there were significant relationships among variables. The results showed that the variables were statistically related as shown in Table 4 . Friend relationship was positively correlated $(\mathrm{r}=0.512, p<0.001)$ to teacher relationship and $(\mathrm{r}=0.148, p<0.001)$ to sports activity. However, it was negatively correlated to $(\mathrm{r}=-354, p<0.001)$ aggression toward others and $(\mathrm{r}=-0.328, p<0.001)$ self. Teacher relationship was positively associated with sports activity $(\mathrm{r}=0.133, p<0.001)$ but negatively related to aggression toward others $(r=0.190, p<0.001)$ and self $(r=-0.153, p<0.001)$. Sports activity was negatively related $(r=-0.059, p<0.05)$ to aggression toward self. Moreover, aggression toward others was positively correlated $(r=0.527, p<0.001)$ to aggression toward self.

Table 4. Correlation analysis.

\begin{tabular}{cccccc}
\hline & FR & TR & SA & TO & TS \\
\hline Friends relationship (FR) & 1 & $0.512^{* * *}$ & $0.148^{* * *}$ & $-354^{* * *}$ & $-0.328^{* * *}$ \\
Teacher relationship (TR) & & 1 & $0.133^{* * *}$ & $-0.190^{* * *}$ & $-0.153^{* * *}$ \\
Sports Activity (SA) & & & 1 & $-0.033^{*}$ & $-0.059^{*}$ \\
Aggression Toward others (TO) & & & & 1 & $0.527^{* * *}$ \\
Aggression Toward self (TS) & & & & 1 \\
\hline & & & &
\end{tabular}

\subsection{Effect of Sports Activity on the Sustainable Social Environment}

Table 5 shows each result after the analysis of multiple regressions. In the first analysis, the researchers tried multiple regressions to examine the influence of sports activity on the friends-self relationship in Model 1 and teachers-self relationship in Model 2. As a result of this analysis, $R^{2}$ was 0.038 , and F value was $12.225^{* * *}$ in Model 1 . More concretely, the researchers found that sports activity was a significant variable to have a good effect on the friend relationship. Subsequently, multiple regression analysis was conducted to identify the effects of sports activity on the teacher relationship. As a result of this analysis, $\mathrm{R}^{2}$ was 0.021 , and $\mathrm{F}$ value was $6.230^{* * *}$ in Model 2, which shows that sports activity was a significant variable to positively increase the teacher relationship.

Then, multiple regression analysis was conducted to identify the direct effects of sports activity and the sustainable social environment factors on juvenile aggression. Table 6 presents the results. As a result of this analysis, it was shown that both teacher and friend relationships were statistically significant on aggression toward others, and only friend relationship was statistically significant on aggression toward oneself. 
Table 5. Multiple regression predicting sustainable social environment factors.

\begin{tabular}{|c|c|c|c|c|c|c|c|}
\hline \multirow{2}{*}{ Variable } & \multicolumn{4}{|c|}{ Model 1} & \multicolumn{3}{|c|}{ Model 2} \\
\hline & & B & SE & $\beta$ & B & SE & $\beta$ \\
\hline \multirow{2}{*}{$\begin{array}{c}\text { Independent } \\
\text { variable }\end{array}$} & Constant & 8.171 & 1.042 & & 10.412 & 1.818 & \\
\hline & SA & 0.214 & 0.03 & $0.172 * * *$ & 0.265 & 0.053 & $0.123^{* * *}$ \\
\hline \multirow{5}{*}{ Control variable } & $\mathrm{HI}$ & -0.005 & 0 & 0.032 & -0.005 & 0 & -0.009 \\
\hline & FE & -0.095 & 0.058 & -0.057 & -0.046 & 0.101 & 0.016 \\
\hline & ME & 0.034 & 0.048 & 0.04 & -0.158 & 0.108 & -0.052 \\
\hline & $\mathrm{HT}$ & 0.005 & 0.062 & 0.019 * & -0.003 & 0.012 & -0.008 \\
\hline & WT & 0.007 & 0.005 & 0.046 & -0.009 & 0.008 & -0.034 \\
\hline Dependent variable & \multicolumn{4}{|c|}{ Friends relationship } & \multicolumn{3}{|c|}{ Teacher relationship } \\
\hline $\mathrm{R}^{2}$ & \multicolumn{4}{|c|}{0.04} & \multicolumn{3}{|c|}{0.021} \\
\hline F value & \multicolumn{4}{|c|}{$12.225 * * *$} & \multicolumn{3}{|c|}{$6.230^{* * *}$} \\
\hline
\end{tabular}

Table 6. Multiple regression predicting aggression factors.

\begin{tabular}{|c|c|c|c|c|c|c|c|}
\hline \multirow{2}{*}{ Variable } & \multicolumn{4}{|c|}{ Model 3} & \multicolumn{3}{|c|}{ Model 4} \\
\hline & & 3 & SE & $\beta$ & B & SE & $\beta$ \\
\hline \multirow{4}{*}{$\begin{array}{l}\text { Independent } \\
\text { variable }\end{array}$} & Constant & 10.578 & 1.127 & & 7.872 & 1.068 & \\
\hline & SA & 0.008 & 0.033 & 0.006 & 0.001 & 0.031 & 0.001 \\
\hline & FR & -0.222 & 0.03 & $-0.205^{* * *}$ & -0.278 & 0.028 & $-0.269^{* * *}$ \\
\hline & TR & -0.057 & -0.091 & $-0.091^{* *}$ & -0.004 & 0.016 & -0.007 \\
\hline \multirow{5}{*}{ Control variable } & $\mathrm{HI}$ & -0.005 & 0.016 & 0.016 & -0.006 & 0 & -0.002 \\
\hline & $\mathrm{FE}$ & 0.054 & 0.03 & 0.03 & 0.015 & 0.058 & 0.009 \\
\hline & ME & -0.003 & -0.002 & -0.002 & 0.054 & 0.062 & 0.03 \\
\hline & HT & 0.004 & 0.521 & 0.016 & 0.023 & 0.007 & 0.101 \\
\hline & WT & -0.006 & -0.036 & -0.036 & -0.005 & 0.005 & -0.035 \\
\hline Dependent variable & \multicolumn{4}{|c|}{ Aggression toward others } & \multicolumn{3}{|c|}{ Aggression toward self } \\
\hline $\mathrm{R}^{2}$ & \multicolumn{4}{|c|}{0.073} & \multicolumn{3}{|c|}{0.087} \\
\hline F value & \multicolumn{4}{|c|}{$17.307^{* * *}$} & \multicolumn{3}{|c|}{$20.810^{* * *}$} \\
\hline
\end{tabular}

${ }^{* * *} p<0.001,{ }^{* *} p<0.01,{ }^{*} p<0.05$. Note: SA is sports activity; FR is friend relationship; TR is teacher relationship;

$\mathrm{HI}$ is household income; FE is father's education; ME is the mother's education; HT is height; WT is weight.

\subsection{Mediating Effect of the Sustainable Social Environment between Sports Activity and Juvenile Aggression}

The researchers conducted a path analysis to find the effect of teacher and friend relationships as mediating variables to the dependent variable (juvenile aggression toward others and oneself), and direct or indirect effect of sports activity as an independent variable to the dependent variable. In the first step, sports activity was inserted on a sustainable social environment. In the second step, sports activity and sustainable social environment were added to juvenile aggression. As a result of this analysis, it has shown that both teacher and friend relationships were statistically significant as a mediation effect variable. This indicates that although sports activity did not directly affect aggression, more sports activity could positively improve the level of teachers-self and friends-self relationships, then reduce both the aggression toward others and oneself as shown in Figure 1. These results show that the effects of sports activity on aggressiveness did not appear directly. However, more sports activity resulted in better friendships and less aggression toward oneself, and better relationships with the teacher resulted in less aggression toward others. 


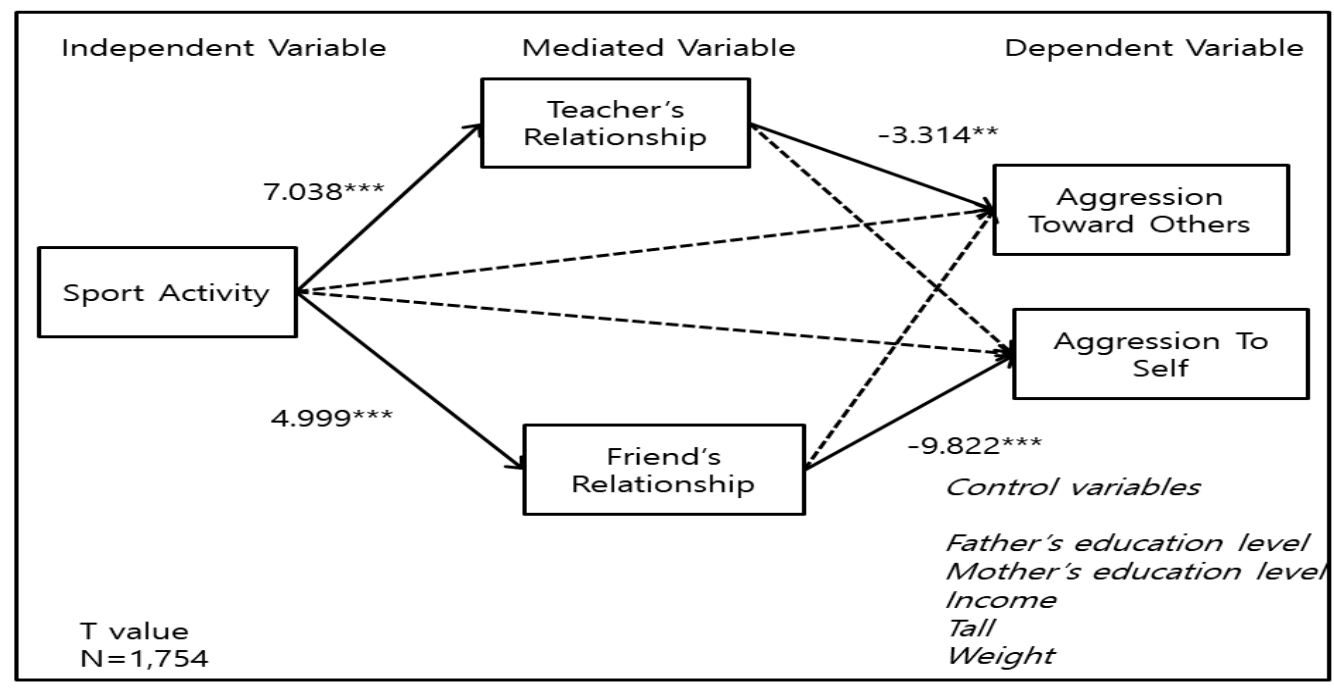

Figure 1. Path analysis of sports activities and sustainable social environment on aggression. ${ }^{* * *} p<0.001$, ** $p<0.01$

\section{Discussion}

As a fundamental social factor along with politics, economy, and culture, sports is the most popular extracurricular activities for adolescents because these factors are strongly related to the socialization in schools [19]. For this reason, the importance of the educational function of sports activity is increasingly important about decreasing juvenile aggression. However, the function of sports activity in school remains controversial, and there are no consistent answers to explain the relationship between sports activity and adolescent development in the education field. In such a context, this study attempted to investigate the positive and negative effects of sports activity about the school environment on juvenile aggression. For this purpose, this study focused on sports activity and its relationship to sustainable social environment factor caused by a variety of factors, including family, school, community, and so on with variables from psychological and social factors. This study also examined whether the sustainable social environment served as a mediating effect between sports activity and juvenile aggression. Therefore, this study used data from the KCYPS, a survey of 2378 adolescents across South Korea. As a result, several noteworthy findings were observed.

Firstly, the analysis indicated that sports activity was significantly related to sustainable social environment (teacher and friend relationships). It is shown that with more sports activity, higher positive level of teacher and friends relationships occurred. In other words, the social necessity of sports activity is positive socialization of adolescence which increases teacher and friend relationships. It is also supported by research findings that sports activity can be adopted as a policy for adolescents' adaptation to school life. Sports can prevent anomie and foster a safe environment for people to release negative emotions [20,21]. At this point, modern sports was exported worldwide as an integral part of the educational system [22-24]. Also, sports promote traditional values and societal arrangements because they help to maintain societal integration [25-28]. From this perspective, sports can be used to solve adolescents' emotional problems, including aggression, according to this empirical evidence pointing to the positive aspects of sports participation related to the sustainable social environment.

Secondly, the analysis indicated that the teachers-self relationship has a mediating influence on aggression toward others. These results show that the role of teachers in schools is essential to ensure psychological growth for adolescents. This result is supported by findings to suggest that it could be possible to reduce the behavioral problem like juvenile aggression (toward others and oneself) when a student has a positive relationship with a teacher [29]. In other words, it is important to develop positive teachers-self relationships to intervene effectively. Thus, the policy maker, school officials, teachers, and school counselors should find various ways to improve teachers-self relationships. 
Lastly, this study statistically verified that the mediating effect of friends-self relationship on aggression toward oneself was identified. The friend relationship was found to be effective in reducing aggression toward oneself. These findings partially support other studies that suggest adolescents with experiences of being ignored or rejected by peers are more anxious and more aggressive than adolescents who do not $[30,31]$. In other words, schools become the center of adolescents' lives, and they spend most of the time with their peers because of the social environment characteristics of adolescents. For these reasons, the development of programs that facilitate interactions with peer groups and provide positive feedback is also necessary.

Despite the practical implications of this study, there are some limitations of this study that need to be addressed. First, the lack of control over the environment in which the participants completed the survey may have affected the findings of this study. Second, the effects of sports activity on the sustainable social environment factors and juvenile aggression (toward others and oneself) were identified. However, this study was more focused on school situation factors. Thus, future research with longitudinal designs should focus on contextual factors to understand mechanisms that contribute to positive developmental outcomes in adolescents.

\section{Conclusions}

This study aimed to assess the causal relationships between sports activity, social and environmental factors, and juvenile aggression based on empirical research to examine the effects of sports on adolescents. This research used the Korean Children \& Youth Panel Survey (KCYPS) which surveyed 2378 adolescents by multistage stratified cluster sampling from 98 schools across South Korea. Socioeconomic backgrounds were used as control variables for this study. The proportion of boys (1091, $52.9 \%$ ) and girls $(970,47.1 \%)$ from the study sample was nearly the same. Regarding the economic level, $62.9 \%$ of respondents said they are middle class, $27.4 \%$ said that they were high-income class, and $8.4 \%$ said they are low-income class. As for the mother's education level, $49.8 \%$ of respondents indicated college graduates, and $47.4 \%$ of respondents said their mother graduated from high school. Also, $2.8 \%$ of respondents indicated graduate school graduation. Next, regarding the father's level of education, the proportion of college graduates were $53.4 \%$ and high school graduates were $41.0 \%$.

As a result of this analysis, it has shown that sports activity had a statistically significant effect on the sustainable social environment factors and teacher and friend relationships, as well as, it was found that sustainable social environment had a statistically significant effect on juvenile aggression toward others and oneself. However, sports activity did not show a direct effect on juvenile aggression toward others and oneself. It indicated that more sports activity could positively improve the level of teachers-self and friends-self relationships and then reduce the aggression toward both others and oneself.

Author Contributions: Conceptualization and methodology, Y.L.; writing-original draft preparation and supervision, S.L.

Funding: This research received no external funding.

Conflicts of Interest: The authors declare no conflict of interest.

\section{References}

1. Back, J.J.; Lee, Y.H. The role of student-teacher relationship on the effects of maltreatment on juvenile delinquency. J. Psychol. 2015, 2, 51-55.

2. Booth, J.A.; Farrell, A.; Varano, S.P. Social control, serious delinquency, and risky behavior: A gendered analysis. Crime Delinq. 2008, 54, 423-456. [CrossRef]

3. Murray, J.; Farrington, D.P. Risk factors for conduct disorder and delinquency: Key findings from longitudinal studies. Can. J. Psychiatry 2010, 55, 633-642. [CrossRef] 
4. Constance, L.C.; Julia, A.M.; Terceira, A.B. Gender, social bonds, and delinquency: A comparison of boys' and girls' models. Soc. Sci. Res. 2005, 23, 357-383.

5. Coalter, F. Sport-for-change: Some thoughts from a skeptic. Soc. Incl. 2015, 5, 19-23. [CrossRef]

6. Fraser-Thomas, J.L.; Cote, J.; Deakin, J. Youth sports programs: An avenue to foster positive youth development. Phys. Educ. Sport Pedagogy. 2005, 10, 19-40. [CrossRef]

7. Erkut, S.; Allison, J.T. Predicting adolescent self-esteem from participation in school sports among Latino subgroups. Hisp. J. Behav. Sci. 2002, 24, 409-429. [CrossRef]

8. Hartmann, D. Theorizing sport as social intervention: A view from the grassroots. Quest 2003, 55, 118-140. [CrossRef]

9. Kelly, L. Sports-based interventions and the local governance of youth crime and antisocial behavior. J. Sport Soc. Issues 2013, 37, 261-283. [CrossRef]

10. Feldman, A.; Jennifer, M. The role of school-based extracurricular activities in adolescent development a comprehensive review and future direction. Rev. Educ. Res. 2005, 75, 503-522. [CrossRef]

11. Matza, D. Position and behavior patterns of youth. In Handbook of Modern Sociology; Robert, E.L., Ed.; Rand McNally: Chicago, IL, USA, 1964; pp. 55-62.

12. Mary, E.D. Sport, and emotions. In Handbook of Sports Studies; Coakley, J., Dunning, E., Eds.; Sage Publications: Thousand Oaks, CA, USA, 2000; pp. 477-479.

13. Mutz, M.; Baur, J. The role of sports in violence prevention: Sports club participation and violent behavior among adolescents. Int. J. Sports Policy Politics 2009, 1, 305-321. [CrossRef]

14. Jo, E.J. The Mediation Effects of Attachment on the Relationship between Adolescent's Self-efficacy and School Adjustment. Korean J. Youth Stud. 2008, 15, 299-321.

15. Kim, J.R. Relationships between Peer Conformity and Delinquency in Middle School Students: The Mediating Effects of Self-Control and the Moderating Effects of Attachment to Teachers. Master's Thesis, Graduate School of Dankook University, Cheonan, Korea, 2014.

16. Connor, E.E.; Dearing, E.; Brian, A.C. Teacher-child relationship and behavior problem trajectories in elementary school. Am. Educ. Time Delinq. Criminal. 2011, 30, 47-87.

17. Ali, Y.; Hamid, K.; Moghaddam, M.M. Depression Treatment by benefiting from Aerobic practice in water. In Proceedings of the 2000 Seoul International Sports Science Congress, Seoul, Korea, 16-18 September 2015.

18. National Youth Policy Institute. KCYPS 1st-7th Waves Survey Data User Guide; National Youth Policy Institute: Seoul, Korea, 2017.

19. Schwery, R.; Cade, D. Sport as a social laboratory to cure anomie and prevent violence. Eur. Sports Manag. Q. 2009, 9, 469-482. [CrossRef]

20. Vermillion, M. Sport participation and adolescent deviance: A Logistic Analysis. Soc. Though Res. 2007, 28, 227-258. [CrossRef]

21. Murdock, T.B. The social context of risk: Status and motivational predictors of alienation in middle school. J. Educ. Psychol. 1999, 91, 38-48. [CrossRef]

22. Roger, C.R.; Andres, W.M. Education, and sports. In Handbook of Sports Studies; Coakley, J., Dunning, E., Eds.; Sage Publications: Thousand Oaks, CA, USA, 2000; pp. 276-290.

23. Fejgin, N. Participation in high school competitive sports: A subversion of school mission or contribution to academic goals? Social. Sports J. 1994, 10, 211-230. [CrossRef]

24. Mckercher, C.M.; Schmidt, M.D.; Sanderson, K.A.; Patton, G.C.; Dwyer, T.; Venn, A.J. Physical activity and depression in young adults. Am. J. Previous Med. 2009, 36, 161-164. [CrossRef] [PubMed]

25. Eitzen, D.S. Social control and sport. In Handbook of Sports Studies; Coakley, J., Dunning, E., Eds.; Sage Publications: Thousand Oaks, CA, USA, 2000; pp. 370-381.

26. Brohm, J. Sport: A Prison of Measured Time; Interlinks: London, UK, 1978.

27. Coakley, J.J. Sport in Society Issues \& Controversies, 6th ed.; WCB McGraw-Hill: New York, NY, USA, 1998.

28. Lee, J.R. Adolescents' Attachments to Parents, Teachers, and Friends, and Delinquencies. Korean Assoc. Hum. Ecol. 2008, 17, 563-574. [CrossRef]

29. Park, J.J. The Longitudinal Analysis of the Relationship between Teacher Attachment and Students' Maladjustment to Schools. J. Korean Teach. Educ. 2011, 28, 333-352. 
30. Kim, Y.K.; Lee, J.K. Relationship on health behavior, body image, self-efficacy and depression by regular exercise among elementary school students. Korea J. Sports Sci. 2005, 14, 265-272.

31. Kim, S.S. The influence of family relationship perceived by adolescents upon depression/anxiety, withdrawn behavior, and aggression: Moderating effect of teacher support and friends support. Korea J. Youth Couns. 2015, 21, 343-364. article distributed under the terms and conditions of the Creative Commons Attribution (CC BY) license (http://creativecommons.org/licenses/by/4.0/). 